\title{
Reducing planning target volume margins decreases dose to parotid glands in head and neck cancers - a dosimetric analysis
}

\author{
Kumar P. ${ }^{1}$, Kumar Chauhan A. ${ }^{2 *}$, Silambarasan N.S. ${ }^{3}$, Garg A. ${ }^{4}$, Yadav R. ${ }^{5}$ \\ DOI: https://doi.org/10.17511/ijmrr.2019.i06.16 \\ 1 Piyush Kumar, Professor, Department of Radiation Oncology, Shri Ram Murti Smarak Institute of Medical Sciences, Bareilly, Uttar Pradesh, \\ India. \\ 2* Arvind Kumar Chauhan, Associate Professor, Department of Radiation Oncology, Shri Ram Murti Smarak Institute of Medical Sciences, \\ Bareilly, Uttar Pradesh, India. \\ 3 Silambarasan N.S., Assistant Professor, Department of Radiation Oncology, Shri Ram Murti Smarak Institute of Medical Sciences, Bareilly, \\ Uttar Pradesh, India. \\ 4 Ayush Garg, Senior Resident, Department of Radiation Oncology, Shri Ram Murti Smarak Institute of Medical Sciences, Bareilly, Uttar \\ Pradesh, India. \\ 5 Rashmi Yadav, Junior Resident, Department of Radiation Oncology, Shri Ram Murti Smarak Institute of Medical Sciences, Bareilly, Uttar \\ Pradesh, India.
}

Introduction: Radiotherapy in head and neck cancers is treated for several weeks and daily setup and reproducibility is a challenge. This daily variability causes setup errors which accounts planning target volume margins. Reduced PTV margins have to be taken to decrease the dose to the parotid glands, without compromising on loco regional control rates. Material and Methods: 420 portal images were evaluated for setup errors in three dimensions (Antero Posterior, Left to Right and Superior to Inferior) which were performed in ten patients of oropharyngeal squamous cell carcinoma. All patients were treated in supine position using immobilization cast. Results: The optimum PTV margins were $4 \mathrm{~mm}$ in LR and SI direction and $7 \mathrm{~mm}$ in AP direction. The PTV parameters (V95, D95, Dmax, Dmean, HI and CI) had no significant difference among different radiotherapy plans with different PTV margins. There was a significant decrease in the dose to right parotid (39.12 Gy to $32.88 \mathrm{~Gy}$; p-0.04), left parotid (37.90 to $31.21 \mathrm{~Gy}$; p-0.03) and parotid combined (38.65 to 31.45 Gy; p-0.01) when 7mm PTV margins were reduced to $4 \mathrm{~mm}$ PTV margins. Conclusion: The decreased PTV margins of $4 \mathrm{~mm}$ decreases the dose to the parotid significantly. The implementation of radiotherapy plans needs to be supplemented by daily IGRT.

Keywords: Head and neck cancers, Planning target volume margin, Parotid gland

\section{Corresponding Author}

Arvind Kumar Chauhan, Associate Professor, Department of Radiation Oncology, Shri Ram Murti Smarak Institute of Medical Sciences, Bareilly, Uttar Pradesh, India.

Email: akcmort@gmail.com

\section{How to Cite this Article}

Kumar P, Chauhan AK, Silambarasan NS, Garg A, Yadav R. Reducing planning target volume margins decreases dose to parotid glands in head and neck cancers - a dosimetric analysis. Int J Med Res Rev. 2019;7(6):552-558.

Available From https://ijmrr.medresearch.in/index. php/ijmrr/article/view/1114
To Browse

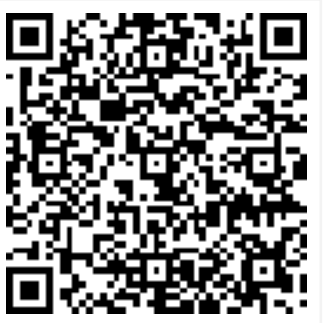

Manuscript Received 2019-12-04

Conflict of Interest No

Review Round 1
2019-12-14
Funding
Nil

Review Round 2
2019-12-20
Ethical Approval
Yes

Review Round 2 Yes
Review Round 3

Accepted 2019-12-23

Plagiarism X-checker $7 \%$

() 2019 by Piyush Kumar, Arvind Kumar Chauhan, Silambarasan N.S., Ayush Garg, Rashmi Yadav and Published by Siddharth Health Research and Social Welfare Society. This is an Open Access article licensed under a Creative Commons Attribution 4.0 International License https://creativecommons.org/licenses/by/4.0/ unported [CC BY 4.0]. 


\section{Introduction}

Intensity modulated radiotherapy (IMRT) is presently the technique of choice for radiation therapy in squamous cell carcinoma of head and neck, since it provides high conformity and steep dose gradients to spare normal tissues, such as the parotid gland.

Despite the tremendous gains achieved with this technique, considerable proportion of these patients still experience troublesome acute and late sideeffects like dryness of mouth and Dysphagia [1-3]. One of the major reasons for these radiation toxicities is the large irradiated volumes being treated due to the use of considerable treatment margins.

The treatment margins may be in the form of clinical target volume (CTV) margin which accounts for the microscopic disease around gross tumor volume (GTV) or planning target volume (PTV). The radiotherapy in head and neck cancers is usually delivered in 6-7 weeks and it is a challenging task to keep the daily setup precision and positioning reproducibility. This daily variability is designated as setup errors which accounts for the PTV margin.

The PTV margins are the institutional protocol depending on their immobilization techniques and use of delivery methods like Image guided radiotherapy (IGRT). Radiation Therapy Oncology Group (RTOG) protocols suggest 3-5 mm margin for the PTV [4-8] while the Eastern Cooperative Oncology Group (ECOG) protocols suggest the PTV margin of about $5 \mathrm{~mm}[9,10]$. A lack of consensus, still exists, regarding the optimal PTV margins to be used in the treatment of head and neck cancer with IMRT. At our institute, the PTV margin of $7 \mathrm{~mm}$ is designated for patients of head and neck treated with IMRT.

The sparing of parotid glands is not often possible with this PTV margin which leads to increased dose to parotid glands and expected long term morbidity of Xerostomia.

To reduce the probability of this long-term morbidity, there is a need to decrease the PTV margins. The present study is done to identify setup errors in present treatment delivery system and see for the feasibility to decrease the PTV margins by creating dummy radiotherapy plans in order to decrease dose to parotid glands.

\section{Materials and Methods}

Study Setting: Department of Radiation Oncology, Shri Ram Murti Institute of Medical Sciences

Duration of study- January 2019 to July 2019.

Study design: Observational study.

Study population: 420 portal images of ten patients of oropharyngeal squamous cell carcinoma were recruited

Study tool: Dosimetric parameters were evaluated.

Ethical consideration and permission: Not required

For the present study, 420 portal images were evaluated for setup errors in three dimensions (Antero Posterior, Left to Right and Superior to Inferior) which were performed in ten patients of oropharyngeal squamous cell carcinoma.

Inclusion Criteria: Age $\geq 18$ years; Karnofsky performance status $>70$; normal haemogram renal function tests \& liver function tests; normal ECHO.

Exclusion Criteria: Patients with prior or synchronous malignancy; patients who underwent prior surgery; distant metastasis; previously treated patients with radiotherapy.

Radiation Therapy Planning: All Patients were treated in supine position on Linear Accelerator by IMRT/ IGRT technique. A fixed 5-point mask system was used for immobilization of the head, neck and shoulders using thermoplastic cast. Planning Contrast enhanced CT scan neck was performed on a flat couch with $3 \mathrm{~mm}$ slice thickness. Target Volume Delineation was done according to Radiation Therapy Oncology Group (RTOG 0225) [5].

The PTV margin of $7 \mathrm{~mm}$ was designated to account for setup errors. Seven to nine coplanar beams using isotropic gantry angles were used. All plans were aimed to achieve a minimum dose of $95 \%$ to a maximum dose of $107 \%$ of the prescribed dose.

Dosimetric parameters assessed in PTV were V95\%, D95(Gy), Dmax, Dmean, Homogeneity Index and Conformity Index. Organs at risk assessed were Brainstem (Dmax), PRV Spine (Dmax), Parotid (Dmean), Cochlea (Dmean), Lips (Dmean) and Mandible (Dmax).

Digital reconstructed radiographs (DRR) were generated in treatment plans. 
The patient positioning was checked by anterior and lateral portal imaging (PI) and compared with DRR. Three dimensional shifts were measured in left to right direction (LR), anterior posterior direction (AP) and superior inferior direction (SI). Data was analysed taking into account negativity and positivity of each displacement.

Positive LR, AP and SI values indicate lateral movement to the right, posterior movement and cranial movement respectively. The protocol for PI (AP and lateral) was 3 times a week on alternate days for 7 weeks. The three dimensional shifts were utilized to calculate systematic and random error values according to Royal college of Radiologists [11]. PTV-margins were calculated according to the three methods proposed by Stroom et al [12], Van Herk et al [13] and ICRU-62 [14].

Dummy radiotherapy plans will be generated using the PTV margins as per the results of the above study. The PTV and OAR parameters will be calculated and compared among older PTV margins (7mm) and new PTV margins.

Statistical Analysis: The data was analyzed using 3 way ANNOVA test and $\mathrm{p}$ value $<0.05$ was considered significant.

\section{Results}

A total of 420 images were evaluated (AP and lateral, thrice in a week for 7 weeks). The mean shift in LR direction was $-0.020 \mathrm{~cm}(-0.44$ to $0.48 \mathrm{~cm})$, in AP direction was $0.010 \mathrm{~cm}(-0.44$ to $0.26 \mathrm{~cm})$ and in SI direction was $-0.002 \mathrm{~cm}(-0.19$ to $0.44 \mathrm{~cm})$. As per the report by Royal college of Radiologist, the calculated individual systematic errors ranged from 0.0113 to $0.183 \mathrm{~cm}$ (LR), 0.098 to $0.873 \mathrm{~cm}(\mathrm{AP})$ and 0.098 to $0.273 \mathrm{~cm}(\mathrm{SI})$ while the individual random errors ranged from -0.186 to $0.66 \mathrm{~cm}$ (LR), -0.075 to $0.236 \mathrm{~cm}(\mathrm{AP})$ and -0.069 to $0.092 \mathrm{~cm}$ (CC) (Table $1,2 \& 3$ ).

The calculated PTV margin by ICRU 62, Stroom and Van Herk's formula is shown in the below table.

Table-1: Systematic \& Random errors in Left to Right Direction (LR).

\begin{tabular}{|c|c|c|c|c|c|c|c|c|c|c|c|}
\hline Week & Day & P1 & P2 & P3 & P4 & P5 & P6 & P7 & P8 & P9 & P10 \\
\hline \multirow[t]{3}{*}{ Week 1} & D1 & -0.22 & -0.44 & -0.15 & -0.04 & -0.11 & 0 & -0.19 & 0 & 0.3 & 0 \\
\hline & D3 & 0.07 & -0.17 & -0.04 & 0.17 & 0 & -0.1 & 0 & 0 & -0.11 & -0.3 \\
\hline & D5 & 0 & -0.19 & -0.19 & -0.15 & 0 & -0.19 & 0 & -0.19 & 0.2 & 0.22 \\
\hline \multirow[t]{3}{*}{ Week 2} & D1 & -0.1 & -0.18 & -0.17 & 0.19 & 0 & -0.15 & 0 & 0 & 0.06 & -0.19 \\
\hline & D3 & 0 & 0.19 & -0.19 & -0.1 & -0.11 & -0.06 & 0.28 & 0 & -0.15 & -0.19 \\
\hline & D5 & 0.19 & -0.18 & -0.17 & -0.1 & -0.19 & -0.11 & 0 & -0.04 & -0.1 & -0.04 \\
\hline \multirow[t]{3}{*}{ Week 3} & D1 & 0.15 & -0.44 & -0.19 & -0.22 & 0.15 & 0.2 & 0.22 & 0.02 & 0.15 & -0.2 \\
\hline & D3 & 0 & 0 & -0.1 & 0.19 & 0.1 & -0.19 & 0.17 & -0.05 & -0.19 & -0.3 \\
\hline & D5 & 0 & -0.1 & 0 & 0.07 & -0.07 & -0.17 & 0.11 & 0 & -0.02 & 0.1 \\
\hline \multirow[t]{3}{*}{ Week 4} & D1 & 0 & 0.04 & 0 & -0.19 & 0 & 0 & 0.17 & -0.1 & 0.3 & -0.27 \\
\hline & D3 & 0.1 & 0.19 & -0.11 & 0.07 & 0.15 & 0 & 0.22 & -0.1 & -0.02 & -0.3 \\
\hline & D5 & 0.15 & 0 & 0.04 & 0 & 0 & -0.19 & 0.15 & -0.11 & 0 & -0.07 \\
\hline \multirow[t]{3}{*}{ Week 5} & D1 & 0 & 0 & 0 & -0.15 & -0.13 & 0 & 0.19 & -0.1 & -0.04 & -0.3 \\
\hline & D3 & 0 & -0.15 & 0 & 0 & -0.1 & 0 & 0.22 & 0 & 0 & -0.27 \\
\hline & D5 & 0.17 & -0.11 & 0 & 0 & -0.19 & -0.17 & 0.15 & 0 & 0.26 & -0.22 \\
\hline \multirow[t]{3}{*}{ Week 6} & D1 & 0.19 & 0 & 0.19 & 0 & 0 & 0 & 0.11 & -0.19 & -0.26 & -0.3 \\
\hline & D3 & 0.3 & -0.11 & 0 & -0.08 & -0.04 & 0 & -0.1 & -0.28 & -0.22 & -0.3 \\
\hline & D5 & -0.22 & 0.3 & 0 & 0 & 0 & -0.2 & -0.1 & -0.22 & -0.19 & -0.4 \\
\hline \multirow[t]{3}{*}{ Week 7} & D1 & -0.01 & 0.07 & 0 & -0.04 & -0.3 & 0.16 & -0.1 & 0 & -0.15 & -0.2 \\
\hline & D3 & -0.04 & 0 & 0.48 & -0.2 & 0.17 & 0.1 & -0.1 & 0.15 & -0.2 & 0 \\
\hline & D5 & 0 & 0 & 0.44 & 0 & 0.33 & 0 & 0 & 0.2 & -0.15 & -0.39 \\
\hline \multicolumn{2}{|c|}{ Systematic error } & 0.035 & -0.061 & -0.008 & -0.028 & -0.016 & -0.051 & 0.067 & -0.048 & -0.025 & -0.187 \\
\hline \multicolumn{2}{|l|}{ Random error } & 0.129 & 0.182 & 0.183 & 0.121 & 0.143 & 0.117 & 0.136 & 0.114 & 0.176 & 0.163 \\
\hline
\end{tabular}

$\mathrm{P}=$ Patient 
Table-2: Systematic \& Random errors in Anterior to Posterior Direction (AP).

\begin{tabular}{|c|c|c|c|c|c|c|c|c|c|c|c|}
\hline Week & Day & P1 & P2 & P3 & P4 & P5 & P6 & P7 & P8 & P9 & P10 \\
\hline \multirow{3}{*}{ Week 1} & D1 & -0.07 & 0.22 & 0 & 0.07 & 0 & 0 & -0.41 & -0.37 & 0.1 & 0.11 \\
\hline & D3 & -0.22 & 0.2 & -0.2 & -0.05 & -0.04 & 0.3 & -0.11 & -0.07 & 0.26 & 0.3 \\
\hline & D5 & -0.11 & -0.14 & -0.1 & -0.22 & 0.11 & 0.3 & 0 & 0.19 & 0.3 & 0 \\
\hline \multirow[t]{3}{*}{ Week 2} & D1 & -0.1 & 0.2 & -0.28 & 0.07 & 0.5 & 0.3 & 0.07 & -0.22 & 0 & 0.04 \\
\hline & D3 & 0 & 0.2 & 0.1 & -0.15 & -0.33 & 0 & 0.11 & -0.15 & 0.19 & -0.19 \\
\hline & D5 & 0 & 0 & 0 & -0.15 & -0.35 & 0.22 & 0 & 0.07 & 0.22 & -0.19 \\
\hline \multirow[t]{3}{*}{ Week 3} & D1 & 0 & -0.22 & 0 & -0.22 & -0.17 & -0.1 & 0.15 & -0.22 & 0.4 & -0.1 \\
\hline & D3 & 0 & -0.16 & 0 & 0 & 0 & 0 & 0 & 0.15 & 0.15 & 0.3 \\
\hline & D5 & 0 & 0.1 & 0 & 0.04 & -0.26 & -0.1 & 0.15 & 0.18 & 0.3 & -0.1 \\
\hline \multirow[t]{3}{*}{ Week 4} & D1 & 0.19 & 0.07 & 0.11 & -0.05 & 0 & 0.11 & 0.22 & 0 & -0.19 & -0.1 \\
\hline & D3 & 0.1 & -0.26 & 0 & 0.11 & -0.22 & 0.2 & 0 & 0.19 & -0.11 & -0.1 \\
\hline & D5 & 0.1 & -0.16 & 0.19 & 0 & -0.22 & 4 & 0.15 & -0.11 & -0.2 & -0.07 \\
\hline \multirow[t]{3}{*}{ Week 5} & D1 & 0 & -0.16 & 0 & 0.26 & 0.16 & 0 & 0.19 & -0.2 & 0.37 & -0.07 \\
\hline & D3 & 0 & -0.26 & 0 & 0 & -0.1 & 0 & 0.15 & 0 & -0.44 & 0.25 \\
\hline & D5 & -0.15 & -0.15 & 0 & 0.09 & -0.2 & 0.05 & 0.1 & -0.17 & 0.1 & 0.11 \\
\hline \multirow[t]{3}{*}{ Week 6} & D1 & 0.1 & 0.15 & -0.26 & 0 & 0 & 0 & 0.3 & -0.1 & -0.15 & -0.2 \\
\hline & D3 & 0.15 & 0.04 & 0.19 & 0.15 & -0.09 & 0 & 0.19 & -0.1 & -0.33 & 0.15 \\
\hline & D5 & -0.07 & -0.1 & 0 & 0 & -0.15 & -0.07 & -0.25 & -0.11 & 0.41 & 0.4 \\
\hline \multirow[t]{3}{*}{ Week 7} & D1 & -0.01 & -0.26 & 0 & 0.11 & -0.04 & -0.15 & -0.2 & 0 & 1 & -0.2 \\
\hline & D3 & -0.04 & 0 & 0 & 0.2 & 0 & 0 & 0 & -0.3 & -0.37 & -0.22 \\
\hline & D5 & 0 & 0 & 0 & 0 & -0.19 & -0.1 & 0 & -0.19 & -0.2 & -0.16 \\
\hline \multicolumn{2}{|c|}{ Systematic error } & -0.006 & -0.033 & -0.012 & 0.012 & -0.076 & 0.236 & 0.039 & -0.073 & 0.086 & -0.002 \\
\hline \multicolumn{2}{|l|}{ Random error } & 0.098 & 0.168 & 0.120 & 0.126 & 0.189 & 0.873 & 0.170 & 0.161 & 0.337 & 0.191 \\
\hline
\end{tabular}

$\mathrm{P}=$ Patient

Table-3: Systematic \& Random errors in Superior to Inferior Direction (SI).

\begin{tabular}{|c|c|c|c|c|c|c|c|c|c|c|c|}
\hline Week & Day & P1 & P2 & P3 & P4 & P5 & P6 & P7 & P8 & P9 & P10 \\
\hline \multirow[t]{3}{*}{ Week 1} & D1 & 0.19 & -0.15 & -0.19 & -0.15 & 0.19 & -0.11 & 0.33 & 0 & 0.33 & 0.07 \\
\hline & D3 & -0.23 & 0.1 & -0.11 & -0.27 & 0.07 & -0.1 & 0 & 0.19 & 0.19 & 0.2 \\
\hline & D5 & -0.7 & 0.22 & 0.1 & 0.22 & 0.3 & 0.15 & 0 & 0 & 0.19 & 0.11 \\
\hline \multirow[t]{3}{*}{ Week 2} & D1 & -0.2 & -0.07 & 0 & 0.07 & -0.3 & 0.15 & 0.19 & 0.11 & -0.19 & 0.19 \\
\hline & D3 & 0 & -0.07 & 0 & -0.15 & 0 & 0.17 & 0 & 0.19 & -0.19 & 0.04 \\
\hline & D5 & -0.11 & -0.11 & 0 & -0.15 & 0.3 & 0.19 & 0.15 & -0.15 & -0.19 & 0.07 \\
\hline \multirow[t]{3}{*}{ Week 3} & D1 & -0.7 & -0.19 & 0.1 & 0.3 & 0.16 & -0.07 & -0.07 & 0.04 & -0.11 & 0.17 \\
\hline & D3 & 0 & -0.16 & -0.1 & 0.06 & 0.1 & 0.1 & 0 & -0.11 & -0.19 & 0.19 \\
\hline & D5 & 0 & -0.19 & 0 & 0 & 0.3 & 0.1 & 0.11 & 0 & -0.19 & -0.1 \\
\hline \multirow[t]{3}{*}{ Week 4} & D1 & 0.5 & 0.11 & 0.05 & -0.15 & 0 & 0.11 & -0.1 & -0.1 & -0.15 & 0.1 \\
\hline & D3 & 0 & 0.1 & 0 & 0 & 0.3 & 0.2 & 0.15 & -0.1 & -0.09 & 0.2 \\
\hline & D5 & -0.2 & -0.2 & -0.19 & 0 & -0.19 & 0.19 & -0.15 & 0 & 0 & 0.19 \\
\hline \multirow[t]{3}{*}{ Week 5} & D1 & 0 & -0.2 & 0 & 0.19 & -0.13 & 0.18 & -0.1 & -0.1 & -0.19 & 0.03 \\
\hline & D3 & 0 & -0.3 & 0 & 0 & -0.1 & 0 & -0.19 & 0 & -0.11 & -0.1 \\
\hline & D5 & 0 & -0.15 & 0 & 0.19 & -0.2 & 0.17 & -0.15 & -0.19 & 0.1 & -0.15 \\
\hline \multirow[t]{3}{*}{ Week 6} & D1 & 0.15 & 0.33 & -0.19 & 0 & 0 & 0.2 & 0.04 & 0.1 & -0.11 & 0.1 \\
\hline & D3 & 0.2 & -0.04 & -0.2 & 0.13 & 0.19 & 0 & 0.1 & -0.1 & 0.11 & -0.19 \\
\hline & D5 & 0.19 & -0.3 & -0.07 & 0 & 0 & 0.15 & -0.19 & 0 & 0.11 & 0.16 \\
\hline \multirow[t]{3}{*}{ Week 7} & D1 & 0.02 & -0.19 & 0 & -0.19 & 0.07 & 0.16 & -0.15 & 0 & -0.19 & 0.1 \\
\hline & D3 & -0.19 & 0 & 0.04 & 0.15 & 0.11 & 0.11 & 0 & -0.15 & 0.4 & 0.15 \\
\hline & D5 & 0 & 0 & -0.19 & 0.19 & -0.19 & -0.1 & 0 & -0.1 & -0.1 & 0.16 \\
\hline \multicolumn{2}{|c|}{ Systematic error } & -0.051 & -0.070 & -0.045 & 0.021 & 0.047 & 0.093 & -0.001 & -0.022 & -0.027 & 0.080 \\
\hline
\end{tabular}




\begin{tabular}{|l|l|l|l|l|l|l|l|l|l|l|}
\hline Random error & 0.273 & 0.166 & 0.098 & 0.156 & 0.183 & 0.109 & 0.138 & 0.107 & 0.186 & 0.120 \\
\hline
\end{tabular}

$\mathrm{P}=$ Patient

Table-4: Calculated PTV margin.

\begin{tabular}{|l|l|l|l|l|l|l|l|l|l|}
\hline \multirow{2}{*}{} & \multicolumn{3}{|c|}{ ICRU 62} & \multicolumn{3}{c|}{ Stroom } & \multicolumn{3}{c|}{ Van Herk } \\
\cline { 2 - 9 } & LR & AP & $\begin{array}{l}\text { SI } \\
(\mathrm{cm})\end{array}$ & $\begin{array}{l}\text { LR } \\
(\mathrm{cm})\end{array}$ & $\begin{array}{l}\text { AP } \\
(\mathrm{cm})\end{array}$ & $\begin{array}{l}\text { SI } \\
(\mathrm{cm})\end{array}$ & $\begin{array}{l}\text { LR } \\
(\mathrm{cm})\end{array}$ & $\begin{array}{l}\text { AP } \\
(\mathrm{cm})\end{array}$ & $\begin{array}{l}\text { SI } \\
(\mathrm{cm})\end{array}$ \\
\hline $\begin{array}{l}\text { CTV-PTV } \\
\text { Margin }\end{array}$ & 0.14 & 0.24 & 0.15 & 0.27 & 0.46 & 0.23 & 0.34 & 0.61 & 0.38 \\
\hline
\end{tabular}

The optimum PTV margins based on these results (Table 4) are $4 \mathrm{~mm}$ in LR and SI direction and $7 \mathrm{~mm}$ in AP direction.

The results of dummy radiotherapy plans using asymmetric PTV margins (LR-4mm, SI-4mm and AP-7mm) and symmetrical PTV margins (4mm in all directions) are compared with PTV margins $(7 \mathrm{~mm}$ in all directions), in terms of PTV and OAR dosimetric parameters (Table $5 \& 6$ ).

Table-5: Comparison of PTV Parameters.

\begin{tabular}{|l|l|l|l|l|}
\hline \multicolumn{1}{|c|}{ PTV Parameters } & \multicolumn{1}{c|}{$\mathbf{m m}$} & \multicolumn{1}{c|}{$4 \mathbf{m m}$} & $\mathbf{4 4 4 \mathrm { mm }}$ & p value \\
\hline V95 (\%) & 98.42 & 98.64 & 98.56 & 0.34 \\
\hline D95 (Gy) & 68.48 & 68.53 & 68.20 & 0.65 \\
\hline Dmax & 73.56 & 73.39 & 73.08 & 0.42 \\
\hline Dmean & 70.21 & 70.07 & 70.11 & 0.80 \\
\hline CI & 0.98 & 0.98 & 0.97 & 0.33 \\
\hline HI & 0.05 & 0.05 & 0.05 & 0.89 \\
\hline
\end{tabular}

All PTV parameters are comparable to each other which suggest that there is no compromise in the dose delivery to the tumor.

Table-6: Dosimetric comparison of Organs at risk.

\begin{tabular}{|l|l|l|l|l|}
\hline \multicolumn{1}{|c|}{ OARs } & $\mathbf{7 m m}$ & $\mathbf{4 4 7 \mathrm { mm }}$ & $\mathbf{4 4 4 \mathrm { mm }}$ & $\mathbf{p}$ value \\
\hline Brainstem (Dmax) & 45.05 & 43.13 & 46.11 & 0.69 \\
\hline PRV Spine (Dmax) & 44.13 & 42.60 & 44.59 & 0.70 \\
\hline Right Parotid (Dmean) & 39.12 & 35.45 & 32.88 & 0.04 \\
\hline Left Parotid (Dmean) & 37.90 & 34.19 & 31.21 & 0.03 \\
\hline Parotid combined (Dmean) & 38.65 & 34.94 & 31.45 & 0.01 \\
\hline Right Cochlea (Dmean) & 29.50 & 25.79 & 21.83 & 0.49 \\
\hline Left Cochlea (Dmean) & 28.54 & 24.09 & 25.01 & 0.77 \\
\hline Lips (Dmean) & 29.57 & 25.04 & 25.99 & 0.33 \\
\hline Mandible (Dmax) & 72.02 & 72.01 & 72.36 & 0.59 \\
\hline
\end{tabular}

The mean dose to left, right and both parotid glands is significantly reduced ( $p-0.03, p-0.04, p-0.01$ respectively) in radiotherapy plans using symmetrical PTV margins ( $4 \mathrm{~mm}$ in all directions) (Table 6).

\section{Discussion}

Reducing PTV margins may reduce dose to the organ at risk like parotid glands. But at the same time there is concern for potential increase in the risk of geographical miss and subsequent increase in loco regional failures. In the study by Caudell et al, [15] it was concluded that using smaller margins or expanding the GTVs volumetrically did not increase the risk of local failure.

Several studies have shown that reducing the radiation dose to parotids and Dysphagia aspiration related structures (DARS) have resulted in significant reduction in dryness of mouth and dysphagia respectively [1,16-19]. Reducing the dose to these specific organs (2.7-4.3Gy) resulted in reduction of severity of radiation toxicity, when the PTV margins were reduced.

In the present study, utilizing the new PTV margins (AP-7mm, LR-4mm, SI- 4mm) after setup error calculations, the dose to right parotid, left parotid and both parotids combined was reduced from 39.12 to $35.45 \mathrm{~Gy}, 37.90$ to $34.19 \mathrm{~Gy}$ and 38.65 to 34.94 Gy respectively (Table 6).

The present study further calculated the dose to the parotid glands by taking another new PTV margin of $4 \mathrm{~mm}$ in all three directions. There was a statistically significant decrease in dose in right parotid ( $p$ $0.04)$, left parotid $(p-0.03)$ and both parotid glands (p-0.01) (Table 6). The results of present indicated to decrease the PTV margins from $7 \mathrm{~mm}$ to $4 \mathrm{~mm}$ in LR and SI direction but no decrease in AP direction.

If we can somehow also decrease the PTV margin in AP direction to $4 \mathrm{~mm}$, there is a significant reduction in dose to the parotids which may lead to decrease in radiation toxicity of parotid glands in terms of xerostomia. The clinical correlation may obviously be inferred by long term follow up.

In a study by Arash Navran et al, [20] reducing the CTV to PTV margin from 5 to $3 \mathrm{~mm}$ and combining with daily Cone beam CT (CBCT) guided volumetric modulated arc therapy, reduced the severity and frequency of radiation related toxicities without affecting the various outcomes (loco regional control rates, disease free survival and overall survival). 
In the present study, if we can incorporate the image guided radiotherapy technique by implementing the protocol of daily $\mathrm{CBCT}$, it seems possible that we may able to treat our group of head and neck cancer patients by reduced PTV margins of $4 \mathrm{~mm}$. Chen et al. [21], provides a direct evidence regarding the concern of reduction in treatment margins may compromising target coverage and leading to marginal geographical misses.

In their study of squamous cell carcinoma of head and neck patients, 367 patients were treated with $5 \mathrm{~mm}$ CTV to PTV margins and 264 patients were treated using $3 \mathrm{~mm}$ margins by IMRT technique. There was no difference in 3 year loco regional control rates ( $78 \%$ and $80 \%$ respectively; $\mathrm{p}-0.75$ ).

There was significant difference in late toxicities in terms of the incidence of gastrostomy-tube dependence at 1 year ( $10 \%$ vs $3 \% ; p-0.001)$ and the incidence of post treatment esophageal stricture ( $14 \%$ vs $7 \% ; p-0.01)$. There was slight decrease in the incidence of Xerostomia (11\% vs $9 \%$ ) though it was not statistically significant ( $p-0.57)$. In our present study, the volumes of parotid glands being irradiated are decreased significantly by decreasing the PTV margins. But whether they will add to the clinical benefit by decreasing the incidence of dryness of mouth, will need long term follow up of at least 2 years.

Few studies have reported the importance of daily imaging for target localization if lesser PTV margins have to be utilized for treatment planning.Den et al [22], in their study of 28 patients treated by IMRT for head and neck cancer showed that in the absence of daily IGRT, a CTV-to-PTV margin of 3.9, 4.1 , and $4.9 \mathrm{~mm}$ is minimally required in the medial-lateral, supero-inferior, and antero-posterior dimensions, respectively, to ensure optimum prescribed treatment dose.

Similarly, another study by Zumsteg et al [23] showed that a substantial proportion of subsequently treated fractions would have been compromised if $<5-\mathrm{mm}$ CTV-to-PTV margins were utilized. Present protocol of our department is $7 \mathrm{~mm}$ PTV margin expansion in all directions. If significant dose reduction to parotid glands has to be achieved, we need to give reduced symmetrical PTV margins of $4 \mathrm{~mm}$ in all directions. This is possible only if we incorporate daily image verification by KV-KV portal imaging or $\mathrm{CBCT}$ imaging in our treatment delivery process.
Jinzhong Yang et al [24] was first to describe the development and application of variable PTV margins in radiotherapy planning. According to them symmetrical PTV margins does not take into account the regional variations due to complicated shaped targets. They utilized the base line PTV margin of $2 \mathrm{~mm}$ with variable margin expanding to $2.5 \mathrm{~mm}$ depending upon the loco regional variations. In the present study our results reveal variable PTV margins of $4 \mathrm{~mm}$ in LR \& SI direction and $7 \mathrm{~mm}$ in AP direction. Our dosimetric calculations using symmetrical PTV expansion of $4 \mathrm{~mm}$ has shown significant decrease in dose to parotids. It will be interesting to look into variable PTV margins by further reducing from $4 \mathrm{~mm}$ symmetrical PTV margins, depending upon the loco regional variations, for any significant advantage in decreasing the radiation dose to the parotid glands.

Limitation of this study: This is the dosimetric analysis and not the application of using lesser PTV margins.

\section{Conclusion}

The present study aimed at demonstrating decreased dose to parotids by decreasing the PTV margins. The implementation of such radiotherapy plans with decreased PTV margins needs to be supplemented by daily IGRT. The clinical impact of such treatment delivery process in terms of decreasing late radiation toxicity of Xerostomia will need long term follow up.

\section{What the study adds to the existing knowledge?}

If we are able to plan head and neck cancer patients with lesser PTV margins, we may be able to decrease normal tissue reactions specially to the parotids which may result in decrease incidence of Xerostomia.

\section{Author's Contribution}

Dr. Piyush Kumar: Drafting the methodology, drafting and verification of manuscript.

Dr. Arvind Kumar Chauhan: Verification of data and verification of manuscript

Mr. Silambarasan NS: Treatment planning

Dr.Ayush Garg: Collection data and manuscript verification 
Dr. Rashmi Yadav: Collection data and manuscript verification

All authors contributed to final manuscript

\section{Acknowledgment}

Authors would like to express their gratitude to patients and thanks to the team of radiation technologists and other staff who were involved in their treatment.

\section{Reference}

01. Nutting $\mathrm{CM}$, Morden JP, Harrington $\mathrm{KJ}$, Urbano TG, Bhide SA, Clark, et al. Parotid-sparing intensity modulated versus conventional radiotherapy in head and

01. neck cancer (PARSPORT)- a phase 3 multicentre randomised controlled trial. Lancet Oncol. $2011 ; 12(2) 127-136$.

doi: $10.1016 / \mathrm{S} 1470-2045(10) 70290-4$ [Crossref]

02. Gulliford SL, Miah AB, Brennan S, McQuaid D, Clark $\mathrm{CH}$, Partridge $\mathrm{M}$, et al. Dosimetric explanations of fatigue in head and neck radiotherapy- an analysis from the PARSPORT Phase III trial. Radiother Oncol. 2012;104(2)205-212.

doi: 10.1016/j.radonc.2012.07.005 [Crossref]

03. Lambrecht $M$, Nevens $D$, Nuyts $S$. Intensitymodulated radiotherapy vs parotid-sparing 3D conformal radiotherapy, Effect on outcome and toxicity in locally advanced head and neck cancer. Strahlenther Onkol. 2013;189(3)223229.

doi: $10.1007 / \mathrm{s} 00066-012-0289-7 \quad$ [Crossref]

04. Radiation Therapy Oncology Group. RTOG 0022 protocol. [Internet]

Available from: [Article] [Crossref]

05. Radiation Therapy Oncology Group. RTOG 0225 protocol. [Internet]

Available from: [Article] [Crossref]

06. Radiation Therapy Oncology Group. RTOG 0435 protocol. [Internet]

Available from: [Article] [Crossref]
07. Radiation Therapy Oncology Group. RTOG 0522 protocol. [Internet]

Available from: [Article] [Crossref]

08. Radiation Therapy Oncology Group. RTOG 0615 protocol. [Internet]

Available from: [Article] [Crossref]

09. Eastern Cooperative Oncology Group. ECOG 2303 protocol. [Internet]

Available from: [Article] [Crossref]

10. Eastern Cooperative Oncology Group. ECOG 2399 protocol. [Internet]

Available from: [Article] [Crossref]

11. The Royal College of Radiologist, Society and College of Radiographers, Institute of Physics and Engineering in Medicine. On targetensuring geometric accuracy in radiotherapy. London- The Royal College of Radiologist. 2008;1-78.

[Crossref]

12. Stroom JC, Hans CJ, Henk H, Andries VG. Inclusion of geometrical uncertainties in radiotherapy treatment planning by means of coverage probability. Int J Radiat Oncol Biol Phys. $1999 ; 43(4) 905-919$.

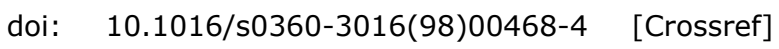

13. Van Herk $M$, Remeijer $P$, Rasch $C$, Lebesque JV. Theprobability of correct target dosage- dosepopulation histograms for deriving treatment margins inradio therapy. Int J Radiat Oncol Biol Phys. 2000;47(4)1121-1135.

doi: $10.1016 / \mathrm{s} 0360-3016(00) 00518-6$ [Crossref]

14. International Commission on Radiation Units and Measurements. ICRU Report 62Prescribing, Recording and Reporting Photon Beam Therapy. [Internet] 1999. (Supplement to ICRU Report; vol 50).

[Crossref]

15. Caudell J], Meredith RF, Spencer SA, Keene KS, Dobelbower MC, Bonner JA. Margin on gross tumor volume and risk of local recurrence in head-and-neck cancer. Int J Radiat Oncol Biol Phys. $2010 ; 76(1) 164-168$.

doi: $10.1016 /$ j.ijrobp.2009.01.037 [Crossref] 
16. Dijkema T, Raaijmakers $C P$, Ten Haken RK, Roesink JM, Braam PM, Houweling AC, et al. Parotid gland function after radiotherapy- the combined Michigan and utrecht experience. Int J Radiat Oncol Biol Phys. 2010;78(2)449-453.

doi: $\quad 10.1016 /$ j.ijrobp.2009.07.1708 [Crossref]

17. Beetz I, Schilstra C, Burlage FR, Koken PW, Doornaert $\mathrm{P}, \mathrm{Bijl} \mathrm{HP}$, et al. Development of NTCP models for head and neck cancer patients treated with three-dimensional conformal radiotherapy for xerostomia and sticky salivathe role of dosimetric and clinical factors. Radiother Oncol. 2012;105(1)86-93.

doi: 10.1016/j.radonc.2011.05.010 [Crossref]

18. Christianen ME, Schilstra C, Beetz I, Muijs CT, Chouvalova O, Burlage FR, et al. Predictive modeling for swallowing dysfunction after primary (chemo) radiation- results of a prospective observational study. Radiother Oncol. 2012;105(1)107-114.

doi: 10.1016/j.radonc.2011.08.009 [Crossref]

19. Little $M$, Schipper $M$, Feng FY, Vineberg $K$, Cornwall C, Murdoch-Kinch CA, et al. Reducing xerostomia after chemo-IMRT for head-andneck cancer- beyond sparing the parotid glands. Int J Radiat Oncol Biol Phys. 2012;83(3)10071014.

doi: $10.1016 /$ j.ijrobp.2011.09.004 [Crossref]

20. Navran A, Heemsbergen $W$, Janssen $T$, Hamming-Vrieze $\mathrm{O}$, Jonker $\mathrm{M}$, Zuur $\mathrm{C}$, et al. The impact of margin reduction on outcome and toxicity in head and neck cancer patients treated with image-guided volumetric modulated arc therapy (VMAT). Radiother Oncol. 2019;130;25-31.

doi: 10.1016/j.radonc.2018.06.032 [Crossref]
21. Chen AM, Yu Y, Daly ME, Farwell DG, Benedict $\mathrm{SH}$, Purdy JA. Long-term experience with reduced planning target volume margins and intensity modulated radiotherapy with daily image-guidance for head and neck cancer. Head Neck. 2014;36(12)1766-1772. doi: 10.1002/hed.23532 [Crossref]

22. Den RB, Doemer A, Kubicek G, et al. Daily image guidance with cone beam computed tomography for head and neck cancer intensitymodulated radiotherapy- a prospective study. Int J Radiat Oncol Biol Phys. 2010;76(5)13531359.

doi: $10.1016 /$ j.ijrobp.2009.03.059 [Crossref]

23. Zumsteg Z, DeMarco J, Lee SP, et al. Image guidance during head-and neck cancer radiation therapy- analysis of alignment trends with inroom cone-beam computed tomography scans. Int J Radiat Oncol Biol Phys. 2012;83(2)712719.

doi: $10.1016 /$ j.ijrobp.2011.08.001 [Crossref]

24. Yang J, Garden AS, Zhang Y, Zhang L, Dong L. Variable planning margin approach to account for loco regional variations in setup uncertainties. Med Phys. 2012;39(8)5136-5144. doi: $10.1118 / 1.4737891$ [Crossref] 